\title{
On the bottleneck and Countermeasures of vocational college enrollment
}

\author{
Ling $\mathrm{Yu}^{1, \mathrm{a}}$, Juan $\mathrm{Gao}^{1, \mathrm{~b}^{*}}$ Haicheng Ning ${ }^{1}$ \\ ${ }^{1}$ Xinjiang Shihezi Vocational College,Shihezi,832000,China \\ aloveanny1981@163.com, bjuanzi922@yeah.net
}

Keywords: Higher vocational colleges; enrollment; problems; countermeasures

\begin{abstract}
Vocational college enrollment is the result of the development of education in China, but there are many problems in the enrollment of Higher Vocational colleges. In this paper, the reason of Vocational Colleges Admissions alone as a starting point, analyzes the causes of existing problems in the higher vocational college enrollment and the existing problems, and puts forward some countermeasures to solve the problems of the Higher Vocational Colleges Admissions alone.
\end{abstract}

\section{Introduction}

At this stage, China is in a critical period of economic restructuring. The development of social economy needs professional and technical personnel of all walks of life, which provides a significant space for the development of Higher Vocational education. Since the college entrance examination system was reinstated in 1977, the selection of talents of higher education in our country mainly depends on the college entrance examination system, which hinders the development of higher vocational education to a certain extent. College entrance examination system cannot be fully applicable to the enrollment of higher vocational education has the following reasons.

1.1The examination content of the college entrance examination system is inconsistent with the direction of Higher Vocational Education

The higher occupational education is a part of higher education, but the higher occupational education and higher education is different from other cultures, more focus on actual occupational skills, pay attention to students' innovation ability and practice ability. The main content of the college entrance examination is the theoretical knowledge of the students. The investigation of students' practical ability has not been reflected. The direction of training examination contents and higher vocational colleges college entrance examination system is different, resulting in some students in the higher vocational schools is at a loss, resulting in a waste of resources for schools and students.

1.2The traditional enrollment order reduces the quality of students in Higher Vocational Colleges

The traditional university enrollment order, at the bottom of university undergraduate enrollment in higher vocational colleges, students are relatively limited, many students in higher vocational colleges is to adjust to the "forced" situation, the practical ability and operation ability is inadequate, not to mention the interest, this to the students and schools are not perfect.

1.3The traditional college entrance examination for higher vocational colleges to increase the invisible burden

In the traditional way of recruitment of college enrollment, vocational college teachers face a lack of experience and interest of students, need to pay more effort, go down for a long time, teachers in higher vocational colleges have negative emotions, to a certain extent affected the quality of teaching in Higher Vocational colleges.

1.4The traditional way of college entrance examination leads to the inferiority of students in Higher Vocational Colleges

In the traditional way of the college entrance examination, there are some people the illusion that the higher vocational education in higher vocational colleges, than undergraduate colleges, vocational college students than undergraduates, so that vocational college students have a certain 
psychological burden, produce inferiority. In addition, adjustment of higher vocational teachers students have no interest in learning, compared to the overall quality of the undergraduate students is generally low, resulting in teachers and students in higher vocational colleges have a feeling of inferiority, the overall quality of education will fall.[1]

\section{Higher vocational colleges enrollment problems}

2.1The overall quality of candidates to be further improved

With the development of the higher vocational college enrollment in higher vocational colleges, social status has been greatly improved, people recognized degree in higher vocational colleges has been greatly improved, the influence of higher vocational colleges has been further expanded, the implementation of separate enrollment of college enrollment plan and the actual enrollment has increased situation. But for high school students, college entrance examination through the entrance of the undergraduate school is the common expectations of parents and students, vocational colleges and parents and students back to the second choice. But the higher vocational colleges enrollment in higher vocational colleges is the requirement of candidates to choose, give up other schools for eligibility, such candidates range will be greatly reduced, so that results are good candidates "behoove" choice of undergraduate colleges, only undergraduate school hopeless poor performance of candidates will choose higher vocational colleges.

2.2The proposition is more difficult

In the process of higher vocational colleges, the proposition is difficult. On the one hand, cultural studies, cultural examination to examine whether students with higher vocational schools, but also with the college entrance examination syllabus knowledge, teachers in Vocational Colleges of higher vocational colleges is very familiar with the knowledge, but for high school knowledge is poorly understood, so it is difficult to grasp the scientific and reasonable proposition. If the proposition is entrusted to other units, it will not only increase the cost, but also lead to the confidentiality of the proposition cannot be guaranteed. On the other side, comprehensive quality testing, higher vocational colleges recruited individually is to find suitable occupation education recruitment way, ensure recruitment can meet the demand of Higher Vocational Colleges occupation, so the recruitment, examination is on the one hand, the overall quality of the test is the key, but how to test the overall quality and occupation requirements become a link difficult proposition in Higher Vocational colleges.[2]

2.3Publicity needs to be further improved

Higher vocational college enrollment propaganda work is generally responsible for enrollment of colleges and universities, the reason college propaganda work time and publicity and other aspects of the cycle resulted in Higher Vocational Colleges enrollment publicity alone with little success, most of the candidates are not aware that Vocational Colleges Admissions alone. In addition, due to the lack of understanding of the various social classes of Vocational Colleges Admissions Policy alone and the community seems to have a lot of false enrollment news, resulting in parents and students of Vocational Colleges Admissions alone skeptical. In addition to parents, many teachers in the school of vocational college admissions policy alone is not very well understood, which led to the recruitment of vocational college enrollment alone is not in place, have yet to be strengthened.

2.4The examination admission guarantee fair

Higher vocational college enrollment is a great progress in recruitment of students in higher vocational colleges, higher vocational colleges have more autonomy and diversification, but the increase in higher vocational colleges. At the same time, fairness of the exam admission work has become a big problem. If the candidates cannot pass the college entrance examination, whether to go to school is determined by the recruitment of schools, so that it is difficult to convince the fairness. In practice, the "back door" phenomenon still exists, therefore, how to set up a set of scientific and reasonable procedures, ensure the recruitment fair, impartial and open, so that more excellent candidates to enter the school of higher vocational colleges is the urgent problems to be solved.

2.5The cost of admission alone is too high

China's college entrance examination system has a set of fixed modes. Each link has a procedural structure and arrangement, so do not need the full participation of each school. But at the present 
stage of Higher Vocational Colleges recruited individually are not mature, has not formed the procedures of the recruitment system, therefore, in the recruitment process in Higher Vocational Colleges to participate in every aspect, such as proposition, publicity, registration, examination, admission, and all departments need to cooperate with each other to complete the higher vocational colleges. Therefore, how to simplify the process of enrollment and reduce the cost of individual enrollment is a massive problem in the higher vocational colleges.

\section{The reasons for the existence of the problem of individual enrollment in Higher Vocational Colleges}

\subsection{Vocational Colleges}

The problems existing in the process of enrolling students in higher vocational colleges are caused by the reasons of Higher Vocational colleges. First, the University's soft power to be promoted. The so-called "soft power" refers to the professional setting, teaching mode and curriculum system of Higher Vocational colleges. However, at present, many vocational colleges or teachers in the classroom at the center of teaching materials, the main body of the lack of professional skills and enhance the ability to match the practice of curriculum, which cannot really cultivate practical talents. Two are the hardware facilities failed to update. Practice teaching in Higher Vocational Colleges or schools rely mainly on Theory Teaching in Higher Vocational College, practice base, practice equipment is obsolete, not updated in a timely manner, there is a big gap with the advanced equipment of enterprises, which is for students after graduation to set up barriers to progress in enterprises. Three are the construction of teachers is not ideal. The number of teachers in higher vocational colleges cannot meet the requirements of teaching, the proportion of the number of teachers and students serious imbalance; teachers structure unreasonable proportion principle, the teachers in Higher Vocational Colleges especially technical teachers should be related to enterprises, relevant occupation post hire technical talents to serve as. But at present, the proportion of full-time teachers in higher vocational colleges is too big. At the same time, the quality of teachers has yet to be improved.[3]

\subsection{Social aspects}

Social recognition of vocational education is not high, resulting in a good student is not willing to ask for Higher Vocational colleges. A light occupation education thought is ingrained, the doctrine of Confucius and Mencius we have a lot of lightweight of academic skills through. Since spring and autumn and Warring States period, our country has despised professional education and despised labor. Therefore, the training of technical personnel of specialized schools, less attention. This concept has continued to this day, a large part of parents and students believe that vocational education is low schooling. Two are the concept of quality and quality of the universal existence. From the imperial examination to the college entrance examination system, are based on the theory of knowledge as the core content of the examination, the evaluation method is mainly based on the score, so students are outstanding or not determined by cultural achievements. There is a huge gap between the standard of vocational education and vocational education. The examination of certified quality and skill level is not accepted by the society and everyone. Therefore, the higher vocational education for the majority of people's values, had to succumb to the traditional evaluation concept, but also led to abnormal development of Higher vocational education.

\subsection{Government}

Policy is an important basis for unifying and guiding people's will and behavior, while policy driven is an important driving force for the development of Higher vocational education. First, the relevant policies to be improved enrollment alone. Higher Vocational Colleges Admissions policy documents to promote the rapid progress of individual enrollment, but also to gradually move towards the right track. The state's policy on individual enrollment cannot meet the needs of the development of Higher Vocational colleges. Two are the lack of enrollment alone enrollment. Higher vocational education is mainly to train students' professional, which identifies the needs to invest a lot of money to ensure the timely updating of software and hardware facilities, in order to meet the needs of society for professional and technical personnel. Although the government's investment in higher vocational education has gradually increased, it still cannot meet the needs of Higher vocational 
education. On admission alone, the cost of a separate enrollment is very high, if the lack of government investment, a lot of work cannot be carried out. Three are the lack of supervision of individual admissions. At present, supervision of the single enrollment in higher vocational colleges is to rely on the internal supervision of the school, so that it cannot guarantee the fairness and justice of the enrollment.

\subsection{Personal aspects}

First, the complex and different levels of students. Students are an important indicator reflecting the situation of individual admissions to colleges and universities, but also the focus of enrollment colleges and universities. The quality, of students directly determines the influence of enrollment institutions. Unlike universities, in different regions, popularity and social influence situation, students will be very different, even with a higher vocational college, in different professions, different students will be great. And the enrollment target of higher vocational colleges includes not only the ordinary high school students, but also the secondary vocational students. As a result of the complexity of the students and the level of the difference is very hard to separate admissions. Two admissions staff qualities to be improved. In college enrollment, the school assigned as recruit personnel, or teachers has become recruit staff. These admissions officers generally do undergo professional training, but also caused a large gap between the level of enrollment staff, and the requirements of the bar.

\section{Improve the vocational college enrollment Countermeasures}

4.1The government should further increase the importance of individual admissions

One is to establish a definite influence of the leadership structure. The government is to set up a higher vocational college entrance examination management institutions, and constantly improve the rules and regulations, and promote the smooth development of the work of individual enrollment. Two are to increase investment in the work of individual enrollment. On the policy of the individual enrollment of outstanding performance of the institutions to give some encouragement, in addition, increase funding, and thus promote the progress of the work of individual admissions. Three are to improve the relevant policies. The government should continue to improve the relevant policies, and constantly improve the quality of the recruitment of staff, to increase the recruitment of vocational colleges, such as unusual enrollment. Scientific and rational policy formulation and the introduction of the need to fully investigate the status qua and needs of college enrollment alone, and learn from the advanced experience at home and abroad.[4]

4.2Schools with separate enrollment should further enhance the visibility of the school

First, the enrollment of colleges and universities to enhance their teaching quality. To strengthen the construction of characteristic culture, we should define the core values of the school, strengthen the communication with the enterprise, integrate the enterprise culture into the school culture, and the two are to improve the overall quality of the teachers. The three is to increase the cooperation efforts to encourage teachers in-depth study, regularly send full-time teachers to enterprises, and hire technical personnel of enterprises to carry out practice teaching to the school; four is to accelerate the infrastructure update, and constantly improve the teaching facilities and the school, that school teaching conditions and adapt to the development of enterprises, enterprises can meet the the demand for talent.

4.3Improve the admissions process to ensure the fairness of enrollment

One is to create a scientific proposition quality monitoring system. In the way of proposition and evaluation standards, taking the professional nature and the basic requirements for students at the standard, and take different forms of examination content, at the same time, we must strictly grasp the construction of test questions. Two are to ensure the effectiveness of propaganda work. College admissions alone will have a planned, step by step to carry out recruitment publicity. Three are to ensure the fairness of enrollment in the multiple examination enrollment. Enrollment of colleges and universities should be aimed at the complexity of students, to adopt flexible and diverse methods of investigation and admission criteria. 


\section{Summary}

In a separate entrance is the development of Higher Vocational Colleges in the development opportunities and challenges, as separate universities still exist in the actual enrollment in the work of many problems, as separate enrollment in higher vocational colleges is to identify problems, and analyze the internal and external reasons of the problems, and then explore the countermeasures and suggestions for Higher Vocational Colleges Admissions alone.

\section{Acknowledgements}

2014 the Ministry of Education Humanities and social sciences research project "the research on the reform of the single entrance examination in Higher Vocational Colleges -- Taking Xinjiang as an example", the project number: 14YJA880079

\section{References}

[1] Yuan S. Current Situation and Countermeasures for the Enrollment of Adult Higher Education in Agricultural Colleges:Example of Yunnan Agricultural University[J]. Journal of Biochemistry, 2013, 153(1):43.

[2]Ohland M W, Yuhasz A G, Sill B L. Identifying and Removing a Calculus Prerequisite as a Bottleneck in Clemson's General Engineering Curriculum[J]. Journal of Engineering Education, 2004, 93(3):253 - 257.

[3]Gonzalez L E, Sutton S K, Pratt C, et al. The Bottleneck Effect in Lung Cancer Clinical Trials[J]. Journal of Cancer Education, 2013, 28(3):488-493.

[4]Joung J, Chia Y K, Sun S. Energy-Efficient, Large-Scale Distributed-Antenna System (L-DAS) for Multiple Users[J]. IEEE Journal of Selected Topics in Signal Processing, 2014, 8(5):954-965. 